\title{
ANALISIS SIFAT FISIS DAN MEKANIS ALUMINIUM (AI) PADUAN DAUR ULANG DENGAN MENGGUNAKAN CETAKAN LOGAM DAN CETAKAN PASIR
}

\author{
Masyrukan \\ Teknik Mesin Universitas Muhammadiyah Surakarta \\ JL. A.Yani Tromol Pos I Pabelan Surakarta 57102
}

\begin{abstract}
ABSTRAK
Penelitian ini bertujuan untuk mengetahui sifat fisis dan mekanis pada aluminium paduan daur ulang yang dicetak dengan menggunakan cetakan logam dan cetakan pasir. Material yang digunakan dalam penelitian ini adalah aluminium paduan yang berasal dari daur ulang aluminium bekas, yang dilebur di dalam dapur krusible tipe ciduk dan dicetak didalam cetakan logam dan cetakan pasir. Alat yang digunakan dalam uji kekerasan, uji struktur mikro, dan uji komposisi kimia secara berturut-turut adalah Vickers hardness tester, Olympus Metallurgycal Microscope, Metal Scan Spectrometer. pengujian kekerasan menggunakan pengujian vickers dengan standar ASTM E 92, pengujian struktur mikro menggunakan standar ASTM E 3 dengan cara melihat spesimen dibawah mikroskop dan pengujian komposisi kimia dilakukan dengan cara menembakkan gas argon kepermukaan spesimen, sehingga hasilnya akan terbaca pada komputer. Spesimen $I H V=98,2 \mathrm{kgf} / \mathrm{mm}^{2}$, spesimen II $H V=104,3 \mathrm{kgf} / \mathrm{mm}$. Sedangkan pada aluminium (Al) paduan dengan cetakan pasir diperoleh Spesimen I HV= 81,2 kgf/mm, spesimen II HV = $83 \mathrm{kgf} /$ $\mathrm{mm}$. Pada uji komposisi kimia pada aluminium paduan dengan cetakan logam didapat kandungan unsur-unsur utama yaitu $\mathrm{Al}=85,96 \%, \mathrm{Si}=5.26 \%, \mathrm{Cu}=4,25 \%$ dan $\mathrm{Zn}=2$,23\%. Komposisi kimia pada aluminiu (Al) paduan dengan cetakan pasir didapat kandungan unsur-unsur utama yaitu $\mathrm{Al}=83,69 \%, \mathrm{Si}=4,83 \%, \mathrm{Cu}=7,44$ $\%$ dan $\mathrm{Zn}=2,01 \%$. Pada pengujian struktur mikro terlihat butiran fasa AlSi pada aluminium paduan cetakan logam memiliki struktur butiran halus (kecil) dengan bentuk memanjang serta jarak antar butirannya rapat. Hal ini menyebabkan hasil coran dengan menggunakan cetakan logam memiliki tingkat kekerasan lebih baik.
\end{abstract}

Kata Kunci: aluminium (Al), cetakan, paduan, logam, pasir.

\section{PENDAHULUAN}

Aluminium $(\mathrm{Al})$ adalah salah satu logam non ferro yang memiliki beberapa keunggulan, diantaranya adalah memiliki berat jenis yang ringan, ketahanan terhadap korosi, dan mampu bentuk yang baik (Diharjo, 1999). Adapun sifat dasar dari aluminium (Al) murni adalah memiliki sifat mampu cor yang baik dan sifat mekanik yang jelek. Oleh karena itu dipergunakan aluminium paduan sebagai bahan baku pengecoran sebab sifat mekanisnya akan dapat diperbaiki dengan menambahkan unsur-unsur lain seperti tembaga $(\mathrm{Cu})$, silisium $(\mathrm{Si})$, mangan $(\mathrm{Mn})$, magnesium (Mg) dan sebagainya (Surdia dkk, 1985). Dengan keunggulan tersebut, maka pemanfaatan material aluminium pada beberapa sektor industri

MEDIA MESIN, Vol. 11, No. 1, Januari 2010, 1 - 7 
menjadi semakin meningkat. Sehingga pemanfaatan kembali aluminium bekas merupakan salah satu alternatif untuk menanggulangi kelangkaan bahan baku aluminium (Al), selain itu akan lebih menghemat sumber daya alam yang ada.

Proses pembentukan aluminium dapat dilakukan dengan berbagai cara, salah satunya menggunakan metode pengecoran dengan menggunakan cetakan. Untuk membuat coran harus dilakukan proses-proses seperti pencairan logam, pembuatan cetakan, menuang dan membersihkan coran. Cetakan dibuat dengan jalan memadatkan pasir, adapun jenis pasir yang sering digunakan adalah pasir alam atau pasir buatan yang mengandung tanah liat. Cetakan pasir mudah dibuat dan memiliki nilai ekonomis yang lebih dibandingkan dengan cetakan logam. Selain menggunakan cetakan pasir juga dipakai cetakan yang dibuat dengan menggunakan bahan logam. Jenis logam yang digunakan pada cetakan ini, titik leburnya harus lebih tinggi dari logam yang dicairkan.

Dari uraian diatas, perlu kiranya untuk mengadakan penelitian terhadap aluminium hasil dari proses daur ulang dengan menggunakan cetakan logam dan cetakan pasir. Sehingga hasil dari penelitian tersebut dapat digunakan sebagai pertimbangan dalam penggunaan cetakan oleh industri pengecoran untuk menghasilkan material atau produk yang baik dan siap pakai.

\section{TINJAUAN PUSTAKA}

Arifin, B (2006), Meneliti tentang pengaruh tembaga $(\mathrm{Cu})$ hingga $5 \%$ pada paduan $\mathrm{Al}$ Si5 untuk cetakan pasir dan logam. Pada penelitian ini Al-Si tidak dapat ditingkatkan sifat mekaniknya dengan perlakuan panas. Tambahan unsur $(\mathrm{Cu})$ atau $(\mathrm{Mg})$ dapat meningkatkan sifat mekanis benda cor setelah dilakukan perlakuan panas. Hasil cor pada cetakan logam menunjukkan sifat mekanik yang lebih baik dan permukaan cor yang lebih halus dibandingkan cetakan pasir. Adanya tambahan tembaga $(\mathrm{Cu})$ hingga 5\% pada paduan Al-Si5 meningkatkan kekerasan dan kuat tarik benda cor baik untuk cetakan pasir maupun cetakan logam.

Proses pengecoran paduan aluminium silikon dilakukan pada dapur krusibel tipe ciduk dengan kapasitas $70 \mathrm{~kg}$, menggunakan bahan bakar minyak solar. Kadar silikon ditambahkan dari ingot Al-Si 20\% dan kadar tembaga dibuat master alloy dalam dapur induksi $\mathrm{Al}-\mathrm{Cu} 20 \%$ dengan menggunakan kawat tembaga. Pengujian tarik dilakukan berdasarkan standar ASTM B2/ B26M spesimen diambil dari hasil cor dengan cetakan logam dan cetakan pasir sebanyak dua buah setiap cetakan. Setelah spesimen tarik jadi langsung dilakukan pemanasan larutan (solution treatment) pada suhu 480-500C dan 500C selama 12 jam kemudian dilanjutkan proses penuaan (artificial aging) pada suhu 175C selama 10 jam.

Untuk solution treatment $500 \mathrm{C}$ dengan bertambahnya kadar tembaga pada benda cor untuk cetakan logam, menunjukkan nilai kekerasan meningkat dan kuat tarik cukup besar, pada solution treatment $520 \mathrm{C}$ nilai kekerasan menurun. sedangkan untuk proses penuaan yang dilakukan setelah pemanasan larutan dapat meningkatkan lagi sifat mekanis benda cor cetakan pasir.

Widiyanto, Y (2006), Meneliti Pengaruh Si dalam Recycling Aluminium Terhadap Fluiditas Dan Struktur Mikro Sebagai Bahan Baku Pembuatan Komponen Sepatu Rem Sepeda Motor. Paduan Al-Si mempunyai sifat fluiditas yang baik, dengan proses recycling, limbah aluminium dapat dimanfaatkan sebagai bahan baku paduan Al-Si. Fluiditas merupakan prinsip utama keberhasilan dalam pengecoran logam maupun paduan logam. Fluiditas yang tidak cukup baik akan membentuk misrun terutama pada bagian yang tipis dari tuangan. Komponen sepatu rem sepeda motor terbuat dari bahan paduan Al-Si melalui proses pengecoran. Sehubungan dengan hal tersebut dilakukan penelitian tentang pengaruh Si terhadap fluiditas dari paduan Al-Si dengan bahan recycling, yang jenis dan komposisi kimianya berbeda-beda. Diawali dengan memadu bahanbahan recycling dengan variasi AL8Si, AL9Si dan AL10Si.

Kemudian dilakukan percobaan pengecoran paduan Al-Si untuk komponen sepatu rem sepeda motor. Pengecoran dilakukan pada temperatur $700^{\circ} \mathrm{C}$, kandungan Si $10 \%$, tempe- 
ratur cetakan $130^{\circ} \mathrm{C}$ dan tekanan dies $120 \mathrm{kgf} /$ $\mathrm{cm}^{\circ}$. Setelah itu lalu diuji komposisi kimia, fluiditas, struktur mikro dan kekerasan. Hasil penelitian menunjukkan bahwa paduan AL8Si, AL9Si dan AL10Si hasil recycling, yang karakteristiknya mendekati produk komponen sepatu rem adalah AL 10Si. Semakin banyak kandungan $\mathrm{Si}$, fluiditas semakin besar dan kecepatan aliran rata-rata logam cair semakin tinggi. Semakin tinggi temperatur, fluiditasnya juga semakin besar. Prosentase fasa $\alpha-\mathrm{Al}$ pada AL8Si $>$ AL9Si $>$ AL10Si, sedangkan fasa Si pada AL8Si < AL9Si < AL10Si. Kekerasan AL8Si > AL9Si > AL10Si, sebab dalam paduan Al-Si mengandung $0,8 \%$ Fe yang menyebabkan pembentukan fasa dalam AL8Si $>$ AL9Si $>$ ALI0Si.

Ahmadi, N (2002), meneliti tentang pengaruh pengecoran batang torak dari aluminium padauan AL-Cu-Ni dengan cetakan pasir dan cetakan logam terhadap kekerasan dan kekuatan tarik. Material ini menggunakan aluminium bekas kendaraan roda dua dan roda empat yang dilebur dalam dapur krusibel yang dicetak dalam bentuk batang torak dengan cetakan logam dan cetakan pasir. Ukuran untuk pengujian tarik menggunakan JIS Z2201 dengan skala 1:5, untuk pengujian kekerasan menggunakan uji vickers. Hasil penelitian menunjukkan hasil cetakan logam mempunyai kekerasan lebih dibanding cetakan pasir, dengan kekerasan rata-rata 109,20 kg/mmdan $81 \mathrm{~kg} /$ mmsedangkan kekuatan tariknya 13,56 kg/ mmdan $9,77 \mathrm{~kg} / \mathrm{mm}$.

Dari penelitian tersebut dapat diketahui unsur-unsur yang terkandung dalam aluminium dan pengaruhnya terhadap sifat fisis dan mekanis aluminium, serta pengaruh dari cetakan yang digunakan untuk pengecoran aluminium terhadap sifat fisis dan mekanis.

\section{METODE PENELITIAN}

\section{Bahan dan Alat}

\section{Bahan}

Bahan baku yang digunakan dalam penelitian ini adalah aluminium bekas yang didaur ulang melalui proses pengecoran.

\section{Alat}

1. Tungkupeleburan

2. Alat tuang

3. Cetakan logam dan cetakan pasir

4. Alat uji struktur mikro

5. Alat uji kekerasan

7. Alatuji komposisi kimia

Untuk mempermudah dalam penelitian maka dibuat diagram alir penelitian seperti gambar 1.

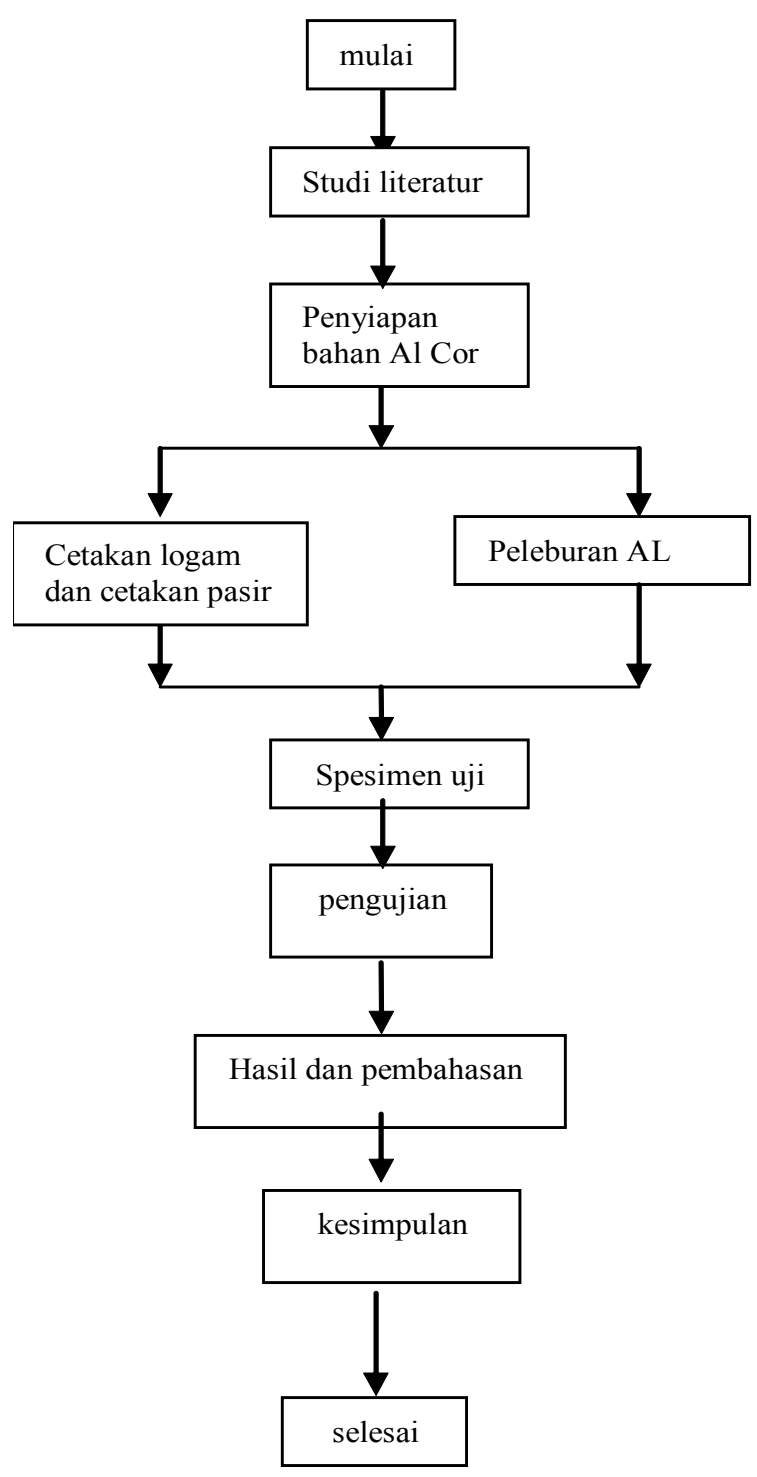

Gambar 1. diagram alir penelitian 
HASIL DAN PEMBAHASAN

\section{Data Uji Komposisi Kimia}

Tabel .1. Data Hasil Uji Komposisi Kimia Aluminium Paduan dari Proses Daur Ulang Dengan Menggunakan Cetakan Logam dan Cetakan Pasir

\begin{tabular}{|c|c|c|c|}
\hline \multirow{2}{*}{ No } & \multirow{2}{*}{ Unsur } & \multicolumn{2}{|c|}{ Prosentase (\%) } \\
\cline { 3 - 4 } & & $\begin{array}{c}\text { Cetakan } \\
\text { logam }\end{array}$ & $\begin{array}{c}\text { Cetakan } \\
\text { pasir }\end{array}$ \\
\hline 1 & $\mathrm{Al}$ & 85.96 & 83.96 \\
\hline 2 & $\mathrm{Si}$ & 5.26 & 4.83 \\
\hline 3 & $\mathrm{Fe}$ & 1.24 & 1.14 \\
\hline 4 & $\mathrm{Cu}$ & 4.25 & 7.44 \\
\hline 5 & $\mathrm{Mn}$ & 0.147 & 0.137 \\
\hline 6 & $\mathrm{Mg}$ & 0.144 & 0.124 \\
\hline 7 & $\mathrm{Cr}$ & 0.0145 & 0.0134 \\
\hline 8 & $\mathrm{Ni}$ & 0.0645 & 0.0609 \\
\hline 9 & $\mathrm{Zn}$ & 2.23 & 2.01 \\
\hline 10 & $\mathrm{Ti}$ & 0.0791 & 0.0729 \\
\hline 11 & $\mathrm{Ca}$ & 0.00 & 0.00 \\
\hline 12 & $\mathrm{~Pb}$ & 0.173 & 0.114 \\
\hline 13 & $\mathrm{Sn}$ & 0.443 & 0.372 \\
\hline 14 & $\mathrm{~V}$ & 0.0020 & 0.00 \\
\hline 15 & $\mathrm{Zr}$ & 0.0116 & 0.0012 \\
\hline
\end{tabular}

Pembahasan Pengujian Komposisi Kimia

Dari hasil pengujian komposisi kimia pada aluminium paduan daur ulang yang dicetak menggunakan cetakan logam dan cetakan pasir, diperoleh sebanyak 15 unsur penyusun pada aluminium paduan cetakan pasir dan 14 unsur pada cetakan logam. Berdasarkan prosentase unsur penyusunnya, kedua jenis aluminium paduan dikategorikan kedalam aluminium paduan Casting Alloy dengan nomor seri mendekati $3 x x . x\{\mathrm{Al}-\mathrm{Si}-\mathrm{Cu})$.
Data Hasil Pengamatan Struktur Mikro

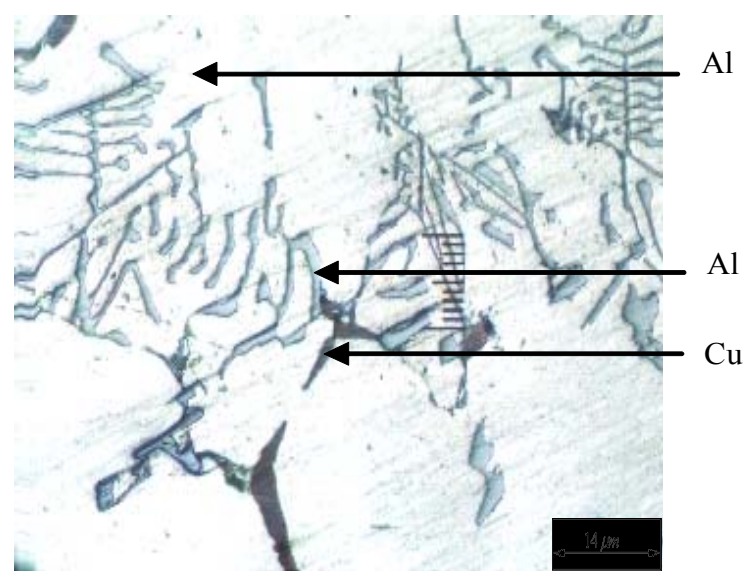

Gambar 3. Struktur Mikro Spesimen Aluminium Daur Ulang dengan Cetakan Logam, dengan Perbesaran $200 x$

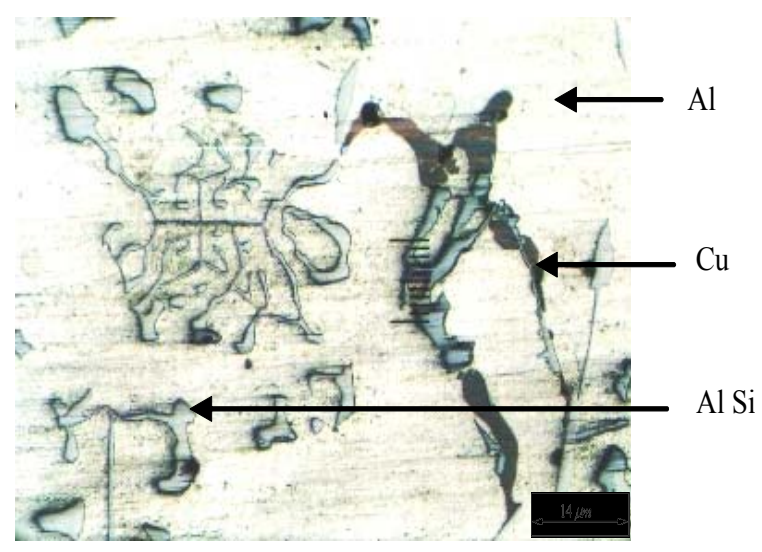

Gambar 4. Struktur Mikro Spesimen Aluminium Daur Ulang dengan Cetakan Pasir, dengan Perbesaran $200 x$

Pembahasan Hasil Pengamatan Struktur Mikro

Berdasarkan hasil pengujian struktur mikro pada aluminium paduan daur ulang dengan menggunakan cetakan logam dan cetakan pasir terbentuk beberapa fasa, diantaranya fasa Al, fasa $\mathrm{CuAl}_{2}$ dan fasa AlSi.

Pada aluminium paduan yang dicetak menggunakan cetakan logam dengan prosentase silikon ( $\mathrm{Si}$ ) 5.26\% dan tembaga $(\mathrm{Cu}) 4.25 \%$, terlihat bahwa distribusi fasa AlSi memiliki struktur butiran dengan ukuran lebih kecil 
memanjang dengan jarak antar butiran yang rapat, dan distribusi fasa $\mathrm{CuAl}_{2}$ lebih cenderung meregang atau struktur butiran yang terbentuk tidak mengelompok. Sedangkan pada aluminium paduan daur ulang yang dicetak menggunakan cetakan pasir, dengan unsur paduan silikon ( $\mathrm{Si}$ ) 4,83\% dan tembaga $(\mathrm{Cu}) 7,44 \%$, memiliki distribusi dan bentuk struktur butiran fasa AlSi yang cenderung menggumpal dengan ukuran butiran lebih besar dan jarak antar butirannya meregang, serta fasa $\mathrm{CuAl}_{2}$ yang terbentuk memiliki struktur butiran yang mengelompok.

Berdasarkan uraian diatas, diperoleh kesimpulan bahwa proses daur ulang aluminium bekas dengan menggunakan cetakan logam menghasilkan distribusi fasa AlSi dan $\mathrm{CuAl}_{2}$ yang lebih merata, dengan struktur butiran lebih halus (kecil) dan jarak antar butiran yang rapat.

\section{Hasil Uji Kekerasan}

Tabel 2. Data Hasil Uji Kekerasan Aluminium Paduan Daur Ulang Dengan Menggunakan Cetakan Pasir

\begin{tabular}{|c|c|c|}
\hline Benda uji & $\begin{array}{c}\mathrm{HV} \\
\left(\mathrm{Kgf} / \mathrm{mm}^{2}\right)\end{array}$ & \multirow{2}{*}{$\begin{array}{c}\mathrm{HV}_{\text {Rata-rata }} \\
\left(\mathrm{Kgf} / \mathrm{mm}^{2}\right)\end{array}$} \\
\hline \multirow{3}{*}{ Spesimen 1 } & 73,5 & \multirow{2}{*}{81,2} \\
\cline { 2 - 2 } & 94,1 & \multirow{2}{*}{81} \\
\cline { 2 - 2 } & 76,1 & \multirow{2}{*}{83,0} \\
\hline \multirow{3}{*}{ Spesimen 2 } & 65,8 & \\
\cline { 2 - 2 } & 97,2 & \\
\cline { 2 - 2 } & 86,2 & \\
\hline
\end{tabular}

Tabel 3. Data Hasil Uji Kekerasan Aluminium Paduan Daur Ulang Dengan Menggunakan Cetakan Logam

\begin{tabular}{|c|c|c|}
\hline \multirow{2}{*}{ Benda uji } & $\begin{array}{c}\mathrm{HV} \\
\left(\mathrm{Kgf} / \mathrm{mm}^{2}\right)\end{array}$ & $\begin{array}{c}\mathrm{HV}_{\text {Rata-rata }} \\
\left(\mathrm{Kgf} / \mathrm{mm}^{2}\right)\end{array}$ \\
\hline \multirow{3}{*}{ Spesimen 1 } & 98,0 & \multirow{2}{*}{98,2} \\
\cline { 2 - 2 } & 101,7 & \multirow{2}{*}{98,2} \\
\cline { 2 - 2 } & 95,0 & \multirow{2}{*}{104,3} \\
\hline \multirow{3}{*}{ Spesimen 2 } & 88,3 & \\
\cline { 2 - 2 } & 123,4 & \\
\cline { 2 - 2 } & 101,2 & \\
\hline
\end{tabular}

Pembahasan Hasil Pengujian Kekerasan

Berdasarkan data hasil pengujian kekerasan Vickers pada aluminium paduan daur ulang yang dicetak dengan menggunakan cetakan logam dan cetakan pasir, diketahui bahwa harga kekerasan rata-rata aluminium paduan yang dicetak dengan menggunakan cetakan logam, untuk spesimen satu sebesar $98.2 \mathrm{~kg} / \mathrm{mm}^{2}$ dan spesimen dua sebesar $104.3 \mathrm{~kg} / \mathrm{mm}^{2}$. Sedangkan harga kekerasan rata-rata pada aluminium paduan yang dicetak menggunakan cetakan pasir, spesimen satu sebesar $81.2 \mathrm{~kg} / \mathrm{mm}^{2}$ dan spesimen dua sebesar $83 \mathrm{~kg} / \mathrm{mm}^{2}$. Dari uraian diatas, diketahui bahwa tingkat kekerasan aluminium paduan yang dicetak menggunakan cetakan logam memiliki nilai kekerasan yang lebih tinggi dibanding harga kekerasan aluminium paduan dengan menggunakan cetakan pasir.

\section{KESIMPULAN}

Berdasarkan analisa dan pembahasan hasil penelitian pada aluminium paduan yang dicetak dengan menggunakan cetakan logam dan cetakan pasir, diperoleh kesimpulan sebagai berikut;

1. Pada aluminium paduan yang dicetak menggunakan cetakan pasir diperoleh 15 unsur penyusun aluminium paduan dan 14 unsur untuk aluminium paduan dengan menggunakan cetakan logam. Dari unsur penyusunnya diperoleh 5 unsur dominan, yang antara lain; $\mathrm{Al}, \mathrm{Si}, \mathrm{Cu}, \mathrm{Zn}$, dan $\mathrm{Fe}$. Besarnya prosentase unsur dominan aluminium Berdasarkan prosentase unsur penyusunnya, kedua jenis aluminium paduan dikategorikan kedalam aluminium paduan Casting Alloy dengan nomor seri mendekati 3xx.x dengan paduan utama Al$\mathrm{Si}-\mathrm{Cu}$.

2. Dari pengamatan struktur mikro pada kedua spesimen uji, terbentuk beberapa fasa yang dapat diamati, yang antara lain : fasa $\mathrm{Al}$ (berwarna terang), fasa AlSi (kelabu terang) dan fasa $\mathrm{CuAl}_{2}$ (berwarna kelabu gelap kecoklatan). Terlihat pada aluminium paduan yang dicetak dengan cetakan logam 
distribusi fasa AlSi dan $\mathrm{CuAl}_{2}$ lebih merata, dengan struktur butiran lebih halus (kecil) dan jarak antar butiran yang rapat. Dengan distribusi dan struktur butiran demikian maka akan dapat meningkatkan nilai kekerasan dari coran yang dihasilkan. Dari uraian diatas dapat disimpulkan bahwa metode pengecoran dengan menggunakan cetakan logam menghasilkan distribusi fasa yang lebih merata bila dibandingkan dengan menggunakan cetakan pasir.

3. Dari pengujian kekerasan diperoleh harga kekerasan rata-rata untuk aluminium paduan dengan cetakan logam spesimen satu sebesar $\mathrm{HV}=98.2 \mathrm{~kg} / \mathrm{mm}^{2}$ dan spesimen dua sebesar $\mathrm{HV}=104.3 \mathrm{~kg} / \mathrm{mm}^{2}$. Sedangkan harga kekerasan rata-rata pada aluminium paduan menggunakan cetakan pasir, spesimen satu sebesar $\mathrm{HV}=81.2 \mathrm{~kg} / \mathrm{mm}^{2}$ dan spesimen dua sebesar $\mathrm{HV}=83 \mathrm{~kg} / \mathrm{mm}^{2}$. Hasil pengujian kekerasan menunjukkan bahwa harga kekerasan pada cetakan logam lebih tinggi. Hal ini disebabkan karena terjadinya penyebaran kristal yang halus dan homogen dari unsur silikon (Si) pada material tersebut.

\section{DAFTAR PUSTAKA}

Beumer, B.J.M., Alih Bahasa : B, S., Anwir, 1994, Ilmu Bahan Logam, Jilid II, cetakan Ke-2, PT. Bhratara, Jakarta.

Dieter, G. E., 1990, Metalurgi Mekanik, Jilid I, Edisi Ke-3, Terjemahan : Sriatie Djaprie, PT. Erlangga, Jakarta.

Purwanto, D., 2004, Pengujian Sifat Fisis dan Mekanis Velg Racing Alumimium Sebelum dan Sesudah di Aging, Tugas Akhir S-1, Teknik Mesin, Universitas Muhammadiyah Surakarta, Surakarata.

Putro, T. H., 2005, Studi Pengecoran Aluminium Silikon (Al+Si) Dengan Cetakan Logam Berpendingin Air dan Udara,Tugas Akhir S-1, Teknik Mesin, Institut Sains dan Teknologi Akprind, Yogyakarta.

Suharto., 1995, Teori Bahan dan Pengaturan Teknik, PT. Rineka Cipta, Jakarta.

Surdia, T., Chijiwa, K., 2000, Teknik Pengecoran Logam, Cetakan Ke-8, PT. Pradnya Paramita, Jakarta.

Surdia, T., Saito, S., 1985, Pengetahuan Bahan Teknik, Cetakan Ke-3, PT. Padnya Paramita, Jakarta.

Van Vlack, L., H., 1992, Ilmu dan Teknologi Bahan, Edisi Ke-5, Terjemahan : Sriatie Djaprie, PT. Erlangga, Jakarta.

Van Vlack, L., H., 2001, Elemen-elemen Ilmu dan Rekayasa Material, Edisi Ke-6, Terjemahan : Sriatie Djaprie, PT. Erlangga, Jakarta 
1998, Annual Book OF ASTM Standards.

-----. 1972, Metals Hand Book Atlas Of Microstruktures of Industrial Alloy, Volume 7, Edisi Ke-8, Metals Park, Ohio. 